\title{
Specific Beliefs about Emotions Are Associated with Different Emotion-Regulation Strategies
}

\author{
Roberta Trincas $^{1 *}$, Elena Bilotta ${ }^{1,2}$, Francesco Mancini ${ }^{1}$ \\ ${ }^{1}$ School of Cognitive Psychotherapy S.r.l., Rome, Italy \\ ${ }^{2}$ Third Center of Cognitive Psychotherapy, Rome, Italy \\ Email: *trincas.roberta@gmail.com
}

How to cite this paper: Trincas, R., Bilotta, E., \& Mancini, F. (2016). Specific Beliefs about Emotions Are Associated with Different Emotion-Regulation Strategies. Psychology, 7, 1682-1699.

http://dx.doi.org/10.4236/psych.2016.713159

Received: September 14, 2016

Accepted: November 15, 2016

Published: November 18, 2016

Copyright $\odot 2016$ by authors and Scientific Research Publishing Inc. This work is licensed under the Creative Commons Attribution International License (CC BY 4.0).

http://creativecommons.org/licenses/by/4.0/

(c) (i) Open Access

\begin{abstract}
Despite evidence pointing to the associations of maladaptive emotion regulation strategies (ERS) with psychopathology, little is known about their underlying mechanisms. Coherently with cognitive models, this study tested the hypothesis that specific beliefs about emotions may be associated with difficulties in emotion regulation and the use of different ERS (reappraisal, suppression, acceptance, rumination, avoidant coping, experiential avoidance). Consistently with the role of avoidance in the cognitive model of worry, we sought testing a mediation pattern where negative beliefs about emotions were connected to maladaptive ERS through experiential avoidance. 309 participants filled out an online questionnaire that measured beliefs about emotions, difficulties in emotion-regulation, and the tendency to adopt different ERS. Results showed that negative beliefs and high fear of emotions were associated with the use of specific ERS and avoidance coping. Fear of depressed mood and anxiety was associated with rumination and emotional avoidance, whereas emotion suppression was mainly associated with fear of anger and positive affect. Also, we found that experiential avoidance mediated the association between beliefs about emotion, rumination and emotional avoidance. Results provided evidence about the specific associations between beliefs about emotions and emotion-regulation processes, suggesting that beliefs about emotions may play a role in orienting specific ER styles.
\end{abstract}

\section{Keywords}

Beliefs about Emotions, Emotion-Regulation Processes, Experiential Avoidance, Fear of Emotion, Difficulties in Emotion-Regulation

\section{Introduction}

Emotion regulation (ER) is defined as a process through which individuals monitor, 
evaluate and modulate their emotions to adequately respond to environmental demands and to accomplish their goals (Rottenberg \& Gross, 2003; Bargh \& Williams, 2007; Gross, 2013). Individuals use regulatory strategies to modify the intensity or type of their emotional experience or the emotion-eliciting event (Gross, 1998; Diamond \& Aspinwall, 2003). Several theoretical models distinguish between adaptive and maladaptive ER strategies (Aldao, Nolen-Hoeksema, \& Schweizer, 2010). Maladaptive strategies may have the paradoxical effect of aggravating negative affect and psychological distress and increasing the incidence of maladaptive behaviours (Selby et al., 2008). Conversely, adaptive strategies are associated with diminished negative affect and decreased arousal in response to emotional stimuli (Dan-Glauser \& Gross, 2013). Generally, reappraisal and acceptance are identified as adaptive ER strategies whereas suppression and distraction are labeled as maladaptive ER strategies. However, other strategies and behaviours involved in the management of negative emotions are also associated with ER, such as rumination, experiential and behavioural avoidance, problem solving, and maladaptive coping strategies (Lazarus \& Folkman, 1984; Gross, 1998; Zeman, Shipman, \& Suveg, 2001; Aldao et al., 2010).

Recently, theoretical models and studies have focused on the core processes of ER. According to the process model (Gross \& Thompson, 2007), cognitive and behavioural ER strategies may be activated either before (antecedent-focused) or after (responsefocused) an emotion occurs. The authors distinguish five emotion regulation strategies: situation selection, situation modification, attentional deployment, cognitive change, and response modulation. Situation selection refers to choosing an approach or avoiding a situation; situation modification acts on a situation itself to modify its emotional effect; attentional deployment refers to focusing on specific aspects of situations; and cognitive change can be used to modify the meaning of a situation. Response modulation defines the attempt to modulate emotion responses (e.g. facial expressions), once such responses are produced. According to functional perspectives, each of these ER strategies may be used in both adaptive and maladaptive ways, depending on the context wherein a strategy is used, its precise function, the ultimate goal of the strategy, and individual beliefs (Philippot, 2013).

With regard to beliefs, appraisal is an important cognitive aspect of the process model and it is pivotal to both emotion generation and emotion regulation (Gross, 2013). A situation needs to be judged as important to the attainment of a goal in order to "activate" an emotion (Gross \& Thompson, 2007). In this model, the appraisal concept involves either appraisals related to situations or appraisals related to emotional responses to such situations (Northoff et al., 2006). In particular, appraisals touching on emotional experiences necessarily involve individuals' beliefs about emotions-both negative and positive-and about their capability of responding to such emotions. The acceptability or unacceptability of emotions- "It's okay to have emotions" and "I shouldn't be feeling in this way"-or their uncontrollability- "I hate myself when I'm sad!" are typical examples of concerns in this regard. According to theorists and clinicians, the first type of appraisal may activate a primary emotion (the initial emotional 
reaction to, and appraisal of, a situation) that does not imply any special type of problems. On the other hand, appraisals about the primary emotion may generate a problematic reaction thereby triggering negative emotions (secondary emotional responses, such as guilt as a result of feeling sad) that exacerbate psychological distress (Greenberg \& Safran, 1990; Greenberg, 2002; Hayes, Luoma, Bond, Masuda, \& Lillis, 2006; Mennin \& Farach, 2007). Some authors define the tendency to negatively evaluate emotional experience as "fear of emotions" (Taylor, Koch, \& Crockett, 1991; Shapiro, 1995; Taylor, 1995; Williams, Chambless, \& Ahrens 1997), characterized by the fear of losing control over both emotions-negative and positive-and behavioural reactions to emotions. In particular, it was observed that "fear of emotions" might interfere with the ability to manage strong emotions (Chambless \& Goldstein, 1981; Heide \& Borkovec, 1984; Taylor et al., 1991). In light of such findings, it is hypothesized that beliefs about the experience of unpleasant emotions and the consequent attempts to control or avoid such emotions may greatly influence both emotion regulation processes and the maintenance of psychopathology (Hayes et al., 2006; Werner \& Gross, 2010).

Various theories have generated specific hypotheses about the beliefs that people may have about their emotions and considered their clinical and theoretical relevance. For example, according to mentalisation theory (Fonagy \& Target, 2003), emotions may be perceived as uncontrollable, or dangerous and inexplicable, and people may not be able to represent and understand them. These beliefs, in turn, may influence the emotion regulation processes (Swenson, Sanderson, Dulit, \& Linehan, 2001; Bateman \& Fonagy, 2004; Manser et al., 2012). Biosocial theory suggests that beliefs about emotions and the tendency to avoid them lead to problems controlling emotions and maintaining distress (Linehan, 1993; Hayes et al., 1996). According to this perspective, some significant beliefs hold that emotions are invalid, overwhelming, shameful, painful, or inaccessible (Swenson et al., 2001), and can cause difficulties in regulating emotions (Linehan, 1993).

Analogously to observations on the relationships between emotional avoidance, beliefs about emotions, and emotion dysregulation (Linehan, 1993), it has recently been argued that experiential avoidance-the tendency to escape private experiences, such as emotions-may be understood as a function of emotion dysregulation (Hayes et al., 1996; Boulanger, Hayes, \& Pistorello, 2010). Iverson et al. (2012) showed that both emotional dysregulation and experiential avoidance were positively associated with BPD symptom severity. The central role of avoidance in the development of regulatory strategies is stated also in Borkovec' model (Borkovec et al., 2004), according to which worry is a regulatory strategy used by individuals that tend to avoid intense emotions. Nevertheless, the specific relationship between experiential avoidance, emotion-regulation and beliefs about emotions, has not yet been examined in the literature. Therefore, we hypothesized that experiential avoidance would be associated with the use of ER strategies in individuals that have negative beliefs about emotions.

At present, few studies focused on the link between emotion beliefs and ER. Tamir et al. (2007) have examined the beliefs about the controllability of emotions and their implications. In particular, they have considered the implicit theory of emotion, which 
postulates that emotions may have a fixed or malleable nature. They have observed that people who view emotions as fixed had lower well-being, greater depressive symptoms and lower social adjustment (Tamir, John, Scrivastava, \& Gross, 2007). Accordingly to metacognitive theories, other authors have recently developed the Belief About Emotions Questionnaire (BAEQ; Manser et al., 2012), designed to measure and evaluate seven types of beliefs about emotions: "overwhelming and uncontrollable"; "shameful"; "irrational"; "invalid and meaningless"; "useless"; "damaging"; and "contagious". Moreover, in healthy subjects, authors found that specific beliefs about emotions as being uncontrollable, dangerous and shameful, were related to BDP symptoms, dysregulation behaviours, and specific coping styles.

The relationship between beliefs about emotions and ER strategies has been not frequently examined, so the aim of the present study is to investigate this specific relationship. Consistently with the literature (Aldao et al., 2010; Wells, 2008; Clark \& Beck, 2009), the aim of the present study was to investigate the associations between negative beliefs about emotions and the adoption of maladaptive regulation strategies (i.e. rumination, suppression, emotional avoidance, and avoidant coping). We expected that individuals with negative beliefs about emotions would choose maladaptive ER strategies. Moreover, we examined if specific beliefs may characterize specific emotion-regulation styles. We hypothesized that different ER strategies would be suited according to the type of emotion to be regulated, to the beliefs about emotions, and consequently, to the goal pursued by the individual.

Moreover, consistently with the role of avoidance in the cognitive model of worry (Borkovec et al., 2004; Cooper et al., 2013), we hypothesized that experiential avoidance would mediate the association between emotion beliefs and ER strategies. We expected an indirect effect of beliefs about emotions on emotion regulation strategies, and we hypothesized this effect would be mediated by the unwillingness to remain in contact with aversive private experiences, i.e., experiential avoidance (Hayes, Strosahl, \& Wilson, 1999) and by the difficulties a person experiences in regulating emotions (Gratz \& Roemer, 2004). Secondly, we hypothesized these two potential mediators could also operate in sequence. Figure 1 represents the conceptual schema we used for the mediation patterns.

\section{Materials and Methods}

\subsection{Sample and Procedure}

Three hundred and nine participants (57.2\% female) filled out an online questionnaire. Participants were enrolled through Mechanical Turk and received a payment for filling out the questionnaire. The questionnaires were administered in a single session and they were completed in 30 minutes. Age ranged from 18 to 73 years $(\mathrm{M}=37.1, \mathrm{SD}=$ 13.3). The sample consisted of $72.8 \%$ White Caucasian, $10.3 \%$ African American, $6.4 \%$ Asian, $2.2 \%$ Other, $0.3 \%$ preferring not to state. The majority of the participants were employees $(51.7 \%)$ and had completed a higher vocational or university education (56.31\%). In the past, $40.4 \%$ of participants had received psychotherapy (type of the 


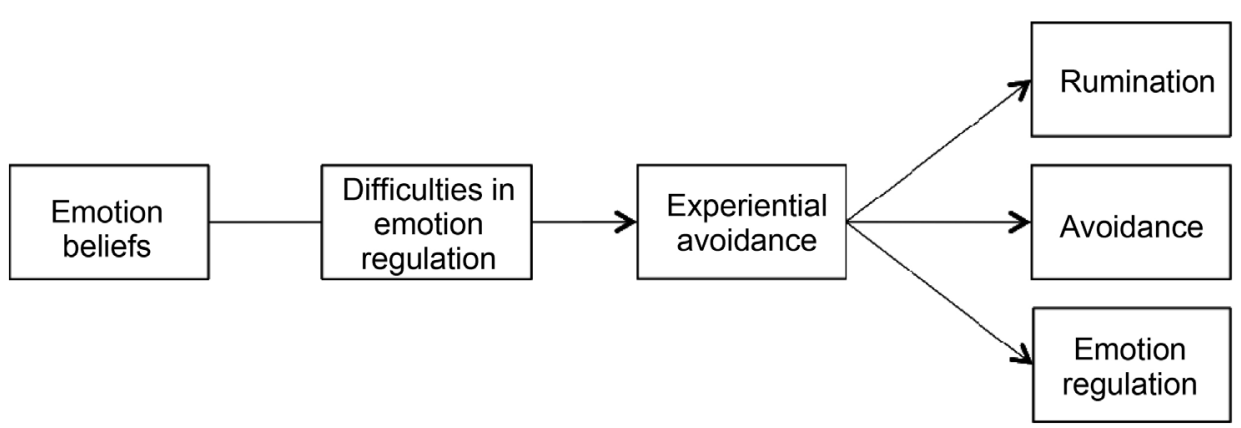

Figure 1. Conceptual schema of mediation patterns.

therapy not specified) or psychological counseling and 30\% of participants had taken medication for psychological problems. At the time, $14 \%$ of the sample were using psychopharmacological drugs and $9.3 \%$ were receiving psychotherapy.

This study was carried out in accordance with the recommendations of "School of Cognitive Psychotherapy S.r.l. Ethics Committee", and of "Italian code (D.lgs. June 30th 2003, n. 196)". All subjects gave written informed consent in accordance with the Declaration of Helsinki.

\subsection{Measures}

\subsubsection{Sociodemographic and Personal Information}

Participants were asked to complete a sociodemographic form that included items regarding age, gender, education, employment, marital status, and the experience of psychotherapy and psychopharmacological drug use.

\subsubsection{Beliefs about Emotions}

1) The Affective Control Scale (ACS; Williams et al., 1997). This scale was designed to assess fear of losing control over emotions or fear of behavioural reactions to emotion. The scale comprised four dimensions: fear of anger ( 8 items; $\alpha=0.75$ ), depression (8 items; $\alpha=0.90$ ), anxiety ( 13 items; $\alpha=0.89$ ), and positive emotion (13 items; $\alpha=$ $0.86)$ (ranging from 1 "very strongly disagree" to 7 "very strongly agree").

2) The Beliefs about Emotions Questionnaire (BAEQ; Manser et al., 2012) was designed to measure beliefs about emotions and consisted of 43 items. A five point scale (from 1 "strongly disagree" to 5 "strongly agree") measured the strength of the belief. The items in the scale reflected themes identified from an in-depth review of the literature as being important perceptions of emotions for those with difficulties regulating their emotions. The questionnaire comprised six dimensions, consisting of beliefs about emotions presented in terms of response options: Overwhelming and Uncontrollable (9 items; $\alpha=0.87$ ); Shameful and Irrational (10 items; $\alpha=0.91$ ); Invalid and Meaningless ( 7 items; $\alpha=0.42$ ); Useless ( 8 items; $\alpha=0.77$ ); Damaging ( 5 items; $\alpha=0.39$ ); and Contagious ( 4 items; $\alpha=0.08$ ).

\subsubsection{Emotion-Regulation Processes}

3) Difficulties in Emotion Regulation Scale (DERS; Gratz \& Roemer, 2004). The 
DERS is a 36-item self-report questionnaire that assesses clinically relevant difficulties in ER with an emphasis on negative emotions. Items are scored on six scales, labeled as Lack of Emotion Awareness (6 items; $\alpha=0.85$ ), Lack of Emotional Clarity (5 items; $\alpha=$ 0.85), Difficulties Controlling Impulsive Behaviours When Distressed (6 items; $\alpha=$ 0.87), Difficulties Engaging in Goal-Directed Behaviour when Distressed (5 items; $\alpha=$ 0.89), Non-acceptance of Negative Emotional Responses (6 items; $\alpha=0.92$ ), and Limited Access to Effective ER Strategies ( 8 items; $\alpha=0.91$ ). Items are scored on a 5-point scale (1 “almost never", 5 "almost always").

4) The Emotion Regulation Questionnaire (ERQ: Gross \& John, 2003) is a 10-item questionnaire which consists of two scales corresponding to two different emotion regulation strategies: cognitive reappraisal ( 6 items; $\alpha=0.88$ ) and expressive suppression ( 4 items; $\alpha=0.80$ ). Instructions ask the subject "some questions about your emotional life, in particular, how you control (that is, regulate and manage) your emotions." The 10 items are rated on a 7-point-Likert scale from 1 "strongly disagree" to 7 "strongly agree".

5) The Stress Reactive Rumination Scale (SRRS; Robinson \& Alloy, 2003) assesses three cognitive tendencies in response to major life stressors: the tendency to focus on the negative attributions and inferences that characterises the negative inferential style (9 items; $\alpha=0.90$ ); the tendency to focus on hopeless cognitions ( 5 items; $\alpha=0.94$ ); and the tendency to focus on active coping strategies and problem-solving solutions ( 7 items; $\alpha=0.83$ ). The 25 items are rated on a 10-point-Likert scale (from 0 "not focus on this at all", to 100 "focus on this to a great extent").

6) The Acceptance and Action Questionnaire-II (AAQ-II; Bond et al., 2011) is a 10-item questionnaire developed to measure psychological inflexibility and experiential avoidance $(\alpha=0.91)$. Participants were asked to rate the trueness of the sentences, ranging from 1 "never true" to 7 "always true".

7) The Need for Affect Scale (NAS; Maio \& Esses, 2001) is a 26-item scale that measures the need to avoid and the need to approach emotion with two separate subscales. The subscale scores can range from -39 to +39 , with higher scores reflecting greater emotional approach and greater emotional avoidance. In this study, we focused only on the avoidance subscale ( 13 items; $\alpha=0.92$ ).

\subsubsection{Coping Style}

8) The Coping Orientation to Problems Experienced (COPE: Carver, Scheier, \& Weintraub, 1989) scale measures how often people undertake a specific coping process when facing difficult or stressful situations. The items, with responses ranging from 1 "I usually don't do this at all" to 4 "I usually do this a lot", referred to five major independent dimensions: Social Support, Positive Attitude, Problem Solving, Turning to Religion and Avoidance Strategies. For the purposes of this study, we exclusively focused on the dimension of Avoidance Strategies, which comprised four subscales, i.e.: denial ( 4 items; $\alpha=0.78$ ), behavioural disengagement ( 4 items; $\alpha=0.81$ ), mental disengagement ( 4 items; $\alpha=0.52$ ), drug and alcohol abuse (4 items; $\alpha=0.45$ ). 


\subsection{Statistical Analyses}

In order to test the relationship between beliefs about emotions, difficulties in emotion regulation and ER strategies, a series of zero order correlations was performed. Data analyses were performed through Statistica 8 (StatSoft. Inc., USA) and SPSS 20. A series of mediation analyses were also run to test the mediation hypothesis. To carry out the multiple mediation analyses, we used the macro PROCESS for SPSS (Hayes, 2013). More specifically, we adopted Model 6 which permits the testing of the significance of the indirect effects through independent mediators (DERS and AAQ) as well as through their sequence (DERS- > AAQ) using bootstrapping sampling.

\section{Results}

Table 1 shows means and standard deviations for all the variables of interest.

\subsection{Correlations}

Given the high number of tests relevant for the current investigation, we adopted a conservative $p$ value $<0.00025$. This conservative cut off should maintain the overall Type I error rate below 0.05. Consistently with our hypothesis, both BAEQ and ACS scales demonstrated significant correlations with difficulties in emotion-regulation, regulation strategies and coping styles (see Table 2(a) \& Table 2(b)). Specific beliefs about emotions (Uncontrollable, Irrational, Damaging and Contagious-BAEQ scales) and difficulties in emotion regulation (DERS subscales) were positively correlated, except for the absence of correlation with BAEQ 3 and 4 (Invalid and Useless subscales) (see Table 2(a)). Beliefs about emotions (BAEQ scores) were negatively correlated with adaptive ERS (reappraisal, acceptance, and active problem solving), and positively correlated with maladaptive ERS (suppression-ERQ, rumination-SRRS, emotional avoidance-NAS and avoidant coping-COPE) (see Table 2(a)).

The fear of emotions (ACS scores) was correlated with both the difficulties in emotion-regulation (DERS) and the considered emotion-regulation strategies (see Table 2(b)). Fear of emotions (ACS) was positively and strongly correlated with emotional avoidance-NAS (0.67), rumination (0.63), hopelessness rumination (0.69), and Avoidant coping-COPE (0.54). Conversely, the fear of emotions was negatively correlated with reappraisal $(-0.30)$ and acceptance $(-0.76)$.

In line with our hypothesis, specific beliefs about emotions were related to different difficulties in emotion regulation. Non-acceptance of emotional responses (DERS 1 subscale) was strongly correlated with the belief that emotions are Irrational (0.76) (see the data marked in Table 2(a)). Impulse control difficulties (DERS 3) were strongly correlated with the fear of Anger (0.61), and the fear of Positive Affect (0.65). The fear of Depressed Mood and Anxiety were positively correlated with Limited access to emotion regulation strategies (Strategies-DERS 5) (DM: 0.80; A: 0.70), Avoidance (DM: 0.60; A: 0.57), and Rumination (DM: 0.59; A: 0.60) (see the data marked in Table 2(b)). Moreover, emotional suppression (ERQ) was mainly related to fear of Anger (0.32) and Positive affect (0.31). Finally, the tendency to have negative secondary reaction to distress 
Table 1. Means and standard deviations for the current level of beliefs about emotions, difficulties in emotion-regulation, and emotion-regulation strategies of the sample.

\begin{tabular}{|c|c|}
\hline & $M(S D)$ \\
\hline ACS-Total score & $3.2(0.9)$ \\
\hline ACS-Anger & $3.5(1.0)$ \\
\hline ACS-Positive affect & $2.8(0.9)$ \\
\hline ACS-Depressed mood & $3.3(1.4)$ \\
\hline ACS-Anxiety & $3.3(1.0)$ \\
\hline BAEQ 1-Uncontrollable & $25.3(7.6)$ \\
\hline BAEQ 2-Irrational & $21.7(8.1)$ \\
\hline BAEQ 3-Invalid & $21.5(3.5)$ \\
\hline BAEQ 4-Useless & $25.8(5.6)$ \\
\hline BAEQ 5-Damaging & $12.6(3.8)$ \\
\hline BAEQ 6-Contagious & $12.0(2.6)$ \\
\hline DERS-Total score & $82.5(26.3)$ \\
\hline DERS 1-Nonacceptance & $13.3(6.2)$ \\
\hline DERS 2-Goals & $14.1(5.1)$ \\
\hline DERS 3-Impulse & $12.5(5.3)$ \\
\hline DERS 4-Aware & $14.2(4.9)$ \\
\hline DERS 5-Strategies & $18.0(7.7)$ \\
\hline DERS 6-Clarity & $10.2(3.9)$ \\
\hline ERQ-Reappraisal & $30.1(6.3)$ \\
\hline ERQ-Suppression & $14.8(5.0)$ \\
\hline AAQ-II-Acceptance & $48.2(12.6)$ \\
\hline SRRS-Negative Inferential Style-Rumination Scale & $50.9(19.3)$ \\
\hline SRRS-Hopelessness Rumination Sub-scale & $22.0(13.8)$ \\
\hline SRRS-Active Problem Solving Sub-scale & $50.5(13.1)$ \\
\hline NAS-Avoidance & $45.2(0.9)$ \\
\hline COPE-Avoidant coping & $29.8(7.8)$ \\
\hline
\end{tabular}

Note: ACS (Affective Control Scale); BAEQ (Beliefs About Emotions Questionnaire); DERS (Difficulties in Emotion Regulation Scale); ERQ (Emotion Regulation Questionnaire); AAQ-II (Acceptance and Action Questionnaire); SRRS (Stress Reactive Rumination Scale); NAS (Negative Affect Scale); COPE-Avoidant coping (Mental disengagement; Behavioural Disengagement; Denial; Substance Use).

(DERS 1) was positively correlated with all ACS subscales: fear of Anger (0.55), Positive Affect (0.54), Depressed Mood (0.52) and Anxiety (0.52) (see the data marked in Table 2(b)).

We ran a moderate regression to test the role of "receiving a psychotherapy" 
(comprising approximately $40 \%$ of the sample) in the relationship between beliefs (ACS and BAEQ scores) and difficulties regulating emotions (DERS scores). The model was not significant $(p>0.05)$.

\subsection{Mediational Analyses}

In the previous section we established the association between BAEQ, ACS and the dependent variables. In this part of the study, we sought to further test whether DERS and AAQ could mediate such associations. Thus, we tested several mediation models in which DERS and AAQ were entered as independent mediators. In addition to this, we also tested whether these potential mediators could also operate in sequence. In other words, we tested whether BAEQ and ACS affected DERS which, in turn, affected AAQ, which finally affected the dependent variable. The two tests differ only on the independent variable used (BAEQ and ACS). The results are reported in Table 3(a) and Table 3(b).

Table 2. (a) Correlations between Beliefs about Emotions Questionnaire scores (BAEQ) and Difficulties in Emotion Regulation Scale (DERS), and emotion-regulation strategies; (b) Correlations between Affective Control Scale scores (ACS) and Difficulties in Emotion Regulation Scale (DERS), and emotion-regulation strategies.

(a)

\begin{tabular}{|c|c|c|c|c|c|c|}
\hline & $\begin{array}{c}\text { BAEQ } 1 \\
\text { Uncontrollable }\end{array}$ & $\begin{array}{l}\text { BAEQ } 2 \\
\text { Irrational }\end{array}$ & $\begin{array}{l}\text { BAEQ } 3 \\
\text { Invalid }\end{array}$ & $\begin{array}{c}\text { BAEQ } 4 \\
\text { Useless }\end{array}$ & $\begin{array}{c}\text { BAEQ } 5 \\
\text { Damaging }\end{array}$ & $\begin{array}{c}\text { BAEQ } 6 \\
\text { Contagious }\end{array}$ \\
\hline DERS-Total score & $0.75^{\star}$ & $0.75^{*}$ & 0.15 & 0.06 & $0.62^{*}$ & $0.41^{*}$ \\
\hline DERS 1-Nonacceptance & $0.55^{\star}$ & $0.76^{*}$ & 0.15 & 0.00 & $0.51^{*}$ & $0.32^{*}$ \\
\hline DERS 2-Goals & $0.71^{*}$ & $0.40^{*}$ & $0.23^{*}$ & 0.01 & $0.47^{*}$ & $0.40^{*}$ \\
\hline DERS 3-Impulse & $0.71^{*}$ & $0.62^{*}$ & 0.12 & 0.00 & $0.57^{*}$ & $0.34^{*}$ \\
\hline DERS 4-Awareness & $0.22^{*}$ & $0.48^{*}$ & -0.06 & $0.28^{*}$ & $0.27^{*}$ & 0.18 \\
\hline DERS 5-Strategies & $0.78^{*}$ & $0.63^{*}$ & 0.19 & 0.02 & $0.59^{*}$ & $0.37^{*}$ \\
\hline DERS 6-Clarity & $0.44^{*}$ & $0.64^{*}$ & 0.01 & -0.01 & $0.45^{\star}$ & $0.28^{*}$ \\
\hline ERQ-Reappraisal & $-0.26^{*}$ & -0.17 & 0.02 & -0.17 & -0.15 & -0.05 \\
\hline ERQ-Suppression & $0.21^{*}$ & $0.45^{*}$ & 0.11 & 0.16 & $0.25^{*}$ & 0.03 \\
\hline AAQ-II-Acceptance & $-0.75^{*}$ & $-0.57^{*}$ & -0.17 & -0.04 & $-0.59^{*}$ & $-0.32^{*}$ \\
\hline $\begin{array}{l}\text { SRRS-Negative Inferential } \\
\text { Style-Rumination Scale }\end{array}$ & $0.68^{*}$ & $0.47^{*}$ & 0.21 & -0.03 & $0.46^{*}$ & $0.41^{\star}$ \\
\hline $\begin{array}{l}\text { SRRS-Hopelessness } \\
\text { Rumination Sub-scale }\end{array}$ & $0.68^{*}$ & $0.53^{*}$ & 0.19 & 0.01 & $0.51^{*}$ & $0.30^{*}$ \\
\hline $\begin{array}{l}\text { SRRS-Active Problem } \\
\text { Solving Sub-scale }\end{array}$ & $-0.24^{*}$ & -0.17 & 0.04 & -0.19 & -0.19 & -0.06 \\
\hline NAS-Avoidance & $0.69^{*}$ & $0.70^{*}$ & $0.28^{*}$ & 0.18 & $0.56^{*}$ & $0.32^{*}$ \\
\hline COPE-Avoidant coping & $0.46^{*}$ & $0.59^{*}$ & 0.07 & 0.00 & $0.47^{*}$ & $0.26^{*}$ \\
\hline
\end{tabular}

${ }^{*}$ Significant at the 0.00025 level. Note: COPE-Avoidant coping (Mental disengagement; Behavioural Disengagement; Denial; Substance Use). 
(b)

\begin{tabular}{|c|c|c|c|c|c|}
\hline & $\begin{array}{l}\text { ACS } \\
\text { Total }\end{array}$ & $\begin{array}{l}\text { ACS } \\
\text { Anger }\end{array}$ & $\begin{array}{c}\text { ACS } \\
\text { Positive affect }\end{array}$ & $\begin{array}{c}\text { ACS } \\
\text { Depressed } \\
\text { mood }\end{array}$ & $\begin{array}{c}\text { ACS } \\
\text { Anxiety }\end{array}$ \\
\hline DERS-Total score & $0.83^{*}$ & $0.67^{*}$ & $0.67^{*}$ & $0.73^{*}$ & $0.71^{\star}$ \\
\hline DERS 1-Nonacceptance & $0.63^{*}$ & $0.55^{*}$ & $0.54^{*}$ & $0.52^{*}$ & $0.52^{*}$ \\
\hline DERS 2-Goals & $0.58^{*}$ & $0.48^{*}$ & $0.35^{*}$ & $0.55^{*}$ & $0.57^{\star}$ \\
\hline DERS 3-Impulse & $0.77^{*}$ & $0.61^{*}$ & $0.66^{*}$ & $0.64^{*}$ & $0.66^{*}$ \\
\hline DERS 4-Aware & $0.41^{*}$ & $0.36^{*}$ & $0.43^{*}$ & $0.31^{*}$ & $0.31^{*}$ \\
\hline DERS 5-Strategies & $0.80^{*}$ & $0.60^{*}$ & $0.59^{*}$ & $0.80^{*}$ & $0.70^{*}$ \\
\hline DERS 6-Clarity & $0.63^{*}$ & $0.53^{*}$ & $0.60^{*}$ & $0.50^{*}$ & $0.49^{*}$ \\
\hline ERQ-Reappraisal & $-0.30^{*}$ & -0.18 & $-0.23^{*}$ & $-0.27^{\star}$ & $-0.32^{*}$ \\
\hline ERQ-Suppression & $0.29^{*}$ & $0.32^{*}$ & $0.31^{*}$ & $0.23^{*}$ & 0.17 \\
\hline AAQ-II-Acceptance & $-0.76^{*}$ & $-0.56^{*}$ & $-0.50^{*}$ & $-0.73^{*}$ & $-0.74^{*}$ \\
\hline $\begin{array}{l}\text { SRRS-Negative Inferential } \\
\text { Style-Rumination Scale }\end{array}$ & $0.63^{*}$ & $0.49^{*}$ & $0.41^{*}$ & $0.59^{*}$ & $0.60^{*}$ \\
\hline $\begin{array}{l}\text { SRRS-Hopelessness } \\
\text { Rumination Sub-scale }\end{array}$ & $0.69^{*}$ & $0.47^{*}$ & $0.47^{*}$ & $0.69^{*}$ & $0.66^{*}$ \\
\hline $\begin{array}{l}\text { SRRS-Active Problem } \\
\text { Solving Sub-scale }\end{array}$ & $-0.26^{\star}$ & -0.15 & -0.16 & $-0.29^{\star}$ & $-0.24^{\star}$ \\
\hline NAS-Avoidance & $0.67^{*}$ & $0.62^{*}$ & $0.48^{*}$ & $0.60^{*}$ & $0.57^{\star}$ \\
\hline COPE-Avoidant coping & $0.54^{*}$ & $0.38^{*}$ & $0.48^{*}$ & $0.48^{*}$ & $0.47^{\star}$ \\
\hline
\end{tabular}

*Significant at the 0.00025 level.

More specifically, Table 3(a) reports all the indirect effects through DERS, AAQ and their sequence for BAEQ, whereas Table 3(b) reports the same indirect effects but with ACS as the independent variable. Both BAEQ and ACS were used as measures of beliefs about emotions. The inspection of $95 \%$ confidence intervals in Table 3(a) revealed a significant overall mediation (i.e., the sum of all indirect effects) for all the dependent variables considered: ERQ suppression, SRRS rumination, SRRS hopelessness, Avoidant Coping, NAS avoidance. The unique indirect effect of BAEQ through DERS was significant for ERQ suppression, SRRS hopelessness, and Avoidant Coping, and not significant for SRRS rumination and NAS avoidance. The unique indirect effect of BAEQ through AAQ was significant for SRRS rumination, SRRS hopelessness and NAS avoidance but not significant for ERQ suppression and Avoidant Coping. Also the sequential indirect effect of BAEQ through DERS followed by AAQ was tested. The analysis revealed that the sequence of DERS and AAQ mediated the effect of BAEQ on SRRS rumination, SRRS hopelessness and NAS avoidance. No indirect sequential effect emerged on ERQ suppression and Avoidant coping.

The same mediational analyses were carried out considering ACS as the independent variable, and DERS, AAQ and the sequence DERS- > AAQ as mediators. Results are 
Table 3. (a) The indirect effects through DERS, AAQ and their sequence for BAEQ; (b) The indirect effects through DERS, AAQ and their sequence for ACS.

(a)

\begin{tabular}{ccccc}
\hline \multirow{2}{*}{$\begin{array}{c}\text { Dependent } \\
\text { Variables }\end{array}$} & Indirect & & \multicolumn{2}{c}{$95 \%$ Bootstrap CI } \\
\cline { 4 - 5 } ERQ-Suppression & Effects & & Lstimate & Upper \\
& TOTAL & 0.19 & 0.05 & 0.32 \\
& Ders & 0.14 & 0.01 & 0.29 \\
& AAQ & 0.02 & -0.02 & 0.08 \\
SRRS-Rumination & Ders $\rightarrow$ AAQ & 0.03 & -0.04 & 0.11 \\
& TOTAL & 0.38 & 0.26 & 0.49 \\
& Ders & 0.03 & -0.09 & 0.13 \\
SRRS-Hopelessness & AAQ & 0.14 & 0.07 & 0.22 \\
& Ders $\rightarrow$ AAQ & 0.21 & 0.14 & 0.29 \\
& TOTAL & 0.48 & 0.38 & 0.58 \\
& Ders & 0.14 & 0.03 & 0.27 \\
& AAQ & 0.13 & 0.07 & 0.22 \\
Avoidant Coping & Ders $\rightarrow$ AAQ & 0.20 & 0.14 & 0.28 \\
& TOTAL & 0.44 & 0.30 & 0.57 \\
& Ders & 0.46 & 0.35 & 0.58 \\
& AAQ & -0.01 & -0.06 & 0.03 \\
& Ders $\rightarrow$ AAQ & -0.02 & -0.08 & 0.05 \\
& TOTAL & 0.16 & 0.03 & 0.29 \\
& Ders & -0.03 & -0.15 & 0.09 \\
& AAQ & 0.07 & 0.03 & 0.14 \\
& Ders $\rightarrow$ AAQ & 0.11 & 0.06 & 0.19 \\
\hline
\end{tabular}

(b)

\begin{tabular}{|c|c|c|c|c|}
\hline \multirow{2}{*}{ Dependent Variables } & \multirow{2}{*}{$\begin{array}{l}\text { Indirect } \\
\text { Effects }\end{array}$} & \multirow{2}{*}{ Estimate } & \multicolumn{2}{|c|}{ 95\% Bootstrap CI } \\
\hline & & & Lower & Upper \\
\hline \multirow[t]{4}{*}{ ERQ-Suppression } & TOTAL & 0.41 & 0.25 & 0.57 \\
\hline & Ders & 0.29 & 0.12 & 0.42 \\
\hline & AAQ & 0.07 & -0.00 & 0.17 \\
\hline & Ders $\rightarrow$ AAQ & 0.05 & 0.00 & 0.12 \\
\hline \multirow[t]{4}{*}{ SRRS-Rumination } & TOTAL & 0.40 & 0.26 & 0.55 \\
\hline & Ders & 0.03 & -0.10 & 0.15 \\
\hline & AAQ & 0.23 & 0.15 & 0.34 \\
\hline & Ders $\rightarrow$ AAQ & 0.15 & 0.08 & 0.23 \\
\hline \multirow[t]{4}{*}{ SRRS-Hopelessness } & TOTAL & 0.43 & 0.32 & 0.57 \\
\hline & Ders & 0.10 & -0.01 & 0.23 \\
\hline & AAQ & 0.20 & 0.13 & 0.31 \\
\hline & Ders $\rightarrow$ AAQ & 0.13 & 0.07 & 0.21 \\
\hline \multirow[t]{4}{*}{ Avoidant Coping } & TOTAL & 0.50 & 0.32 & 0.67 \\
\hline & Ders & 0.52 & 0.39 & 0.66 \\
\hline & AAQ & -0.01 & -0.08 & 0.07 \\
\hline & Ders $\rightarrow$ AAQ & -0.01 & -0.06 & 0.04 \\
\hline \multirow[t]{4}{*}{ NAS-Avoidance } & TOTAL & 0.55 & 0.37 & 0.72 \\
\hline & Ders & 0.23 & 0.10 & 0.38 \\
\hline & AAQ & 0.19 & 0.10 & 0.30 \\
\hline & Ders $\rightarrow$ AAQ & 0.12 & 0.07 & 0.21 \\
\hline
\end{tabular}


reported in Table $3(\mathrm{~b})$. As in the previous analysis, overall indirect effect was significant for all the dependent variables: ERQ suppression, SRRS rumination, SRRS hopelessness, Avoidant Coping, NAS avoidance. The unique indirect effect of DERS was significant on ERQ suppression, Avoidant coping and NAS avoidance, whereas it was not significant on SRRS rumination, and SRRS hopelessness. The unique indirect effect of AAQ was significant on SRRS rumination, SRRS hopelessness and NAS avoidance but not on ERQ suppression and Avoidant coping. Finally, the sequential indirect effect was significant on ERQ suppression, SRRS rumination, SRRS hopelessness, and NAS avoidance but not on Avoidant coping.

\section{Discussion}

The present study was driven by recent findings about the relationship between beliefs about emotions, behaviours associated with emotion dysregulation, and specific ER processes (Tamir et al., 2007; Manser et al., 2012; De Castella et al., 2013). In particular, we aimed to investigate the association of beliefs about emotions with maladaptive ER strategies and difficulties regulating emotion. Results supported the hypothesis that beliefs about emotions are associated with specific ER processes.

We observed that high fear of emotions and beliefs that emotions were uncontrollable irrational and damaging were associated with difficulties regulating emotions, in particular, with the tendency to have a negative secondary reaction to distress, with lack of emotional clarity, and with difficulties in engaging in goal-directed behaviours. The belief that emotions are uncontrollable was associated with higher use of rumination and emotional avoidance and lower use of acceptance, reappraisal and problem solving. This result is consistent with findings of other studies showing that people who considered emotions as uncontrollable were less likely to use adaptive emotion-regulation strategies, such as cognitive reappraisal, in their daily lives (Tamir et al., 2007; De Castella et al., 2013).

Our findings were consistent with our hypothesis about the specific association between beliefs about emotions and regulation strategies. For example, it would be assumed that the beliefs, strategies and behaviours were generally related in ways that might be expected, such that those who believed their emotions to be threatening, would be more likely to avoid emotional experiences (ER strategy), and, consequently, would have less clarity about their emotions (difficulty in ER).

Secondly, we tested the idea that specific beliefs were associated with different regulation styles. Fear of specific emotions (depressed mood, anxiety, anger and positive affect) (as measured by ACS) was correlated with the use of different ER strategies. Negative beliefs about the uncontrollability of depressed mood and anxiety were associated with higher use of rumination and emotional avoidance, and with a limited access to ER strategies. Whereas emotion suppression was mainly associated with the belief that anger and positive affect may have consequences on the control over own actions, and impulse control difficulties. In line with our findings, these specific associations might be explained by the idea that individuals regulate their behaviours according to differ- 
ent goals and values (Carver \& Sheier, 1998), thus ER strategies could be oriented by specific goals. For example, rumination would be an attempt to find a solution in response to the fear of being overcome by depression; emotional avoidance could be a strategy oriented by the belief that anxiety is uncontrollable and motivated by the goal to avoid loss of control; moreover, anger and positive emotions seem to be mainly associated with the fear to loose control, and difficulties in regulating impulses and behaviours. Thus, suppression of these emotions would be motivated by the fear to loose self-control and by the goal to avoid negative judgment or to cause damages or pain to others. These results were in line with several clinical observations. First, emotion avoidance is a regulation strategy that plays a role in maintaining both anxiety and mood disorders. For example, it can be used as a regulation strategy for the purpose of avoiding acute episodes of fear or to regulate sadness (Campbell-Sills \& Barlow, 2007). Secondly, these findings confirm the idea that rumination is an attentional strategy for reducing emotional discomfort (Papageorgiou \& Wells, 2001; Watkins \& Baracaia, 2001; Gross \& Thompson, 2007). Finally, our results are consistent with findings of other studies that observed that suppression was used to regulate many negative emotions, such as anger, and to decrease the subjective experience of positive emotions (Gross \& Levenson, 1997; Gross, 1998).

The tendency to have a negative secondary reaction to distress, measured by the Non-Acceptance scale of DERS, was strongly correlated with higher negative beliefs about emotions, in particular, with the belief that emotions are irrational. In other terms, the idea about irrationality of emotions was associated with feelings of guilt, shame, embarrassment, and weakness in reaction to emotional experience. From a clinical perspective, if an individual believes that emotions are irrational, experiencing emotions could be an aversive event, because potentially leading to being judged an irrational person. Thus, self-concept might be negatively affected, and this could be considered an example of secondary problem. We sustain that beliefs about emotions are instrumental in determining a secondary emotional response that might exacerbate and maintain the primary reaction and the consequent regulation attempts (Ellis, 2003; Clark \& Beck, 2010; Greenberg \& Safran, 1990; Greenberg, 2002; Hayes et al., 2006; Mennin \& Farach, 2007). Considering an emotion as unacceptable or aversive, can affect the way a person regulates the emotional state. For example, people suffering from social phobia tend to worry about the negative consequences of their anxiety in social contexts, such as that of being judged stupid. From a clinical perspective, this evaluation is considered responsible of the persistence of anxiety (primary problem; Clark \& Beck, 2010). Consistently with this assumption, a sub-scale of DERS considers the tendency to have a negative secondary or non-accepting reaction to one's own distress (i.e. beliefs that emotions are shameful) as a specific difficulty in the emotion regulation process. In line with our findings, we assume the existence of a vicious circle, by which the fear of emotions and their associated beliefs maintain or exacerbate both emotional responses and the difficulties in ER, which, in turn, reinforce both beliefs about emotions and the use of unhelpful attempts to regulate emotional reactions, such as by, for 
example, experiential and behavioural avoidance.

Results showed that high fear of emotions and beliefs that emotions are uncontrollable, irrational and damaging are related withs specific behaviours, such as those involved in avoidant coping (i.e., behavioural disengagement, denial, substance use and mental disengagement). Concerning the role of experiential avoidance, mediation findings showed that people who had negative beliefs about emotions, difficulties regulating emotions, and a tendency to experiential avoidance, used specific ER strategies, such as rumination and avoidant style (i.e. suppression, emotional avoidance, and substance use). We may assume that these people tended to avoid the emotional experiences using cognitive and behavioural strategies. This is in line with the idea that experiential avoidance may be understood as a function of emotion regulation that does not simply refer to internal experiences (feeling emotions strongly), but also to the associated overt behavioural response (Boulanger et al., 2010). Finally, the mediation results demonstrated that experiential avoidance might have a role in the association between beliefs about emotions and rumination. To explain this interrelation we hypothesized the same mechanisms indicated in Borkovec' model (2004) and Alloy and colleagues (2000), which states that ruminative worrying is a form of emotional avoidance that plays a role in the maintenance of anxiety in generalized anxiety disorder (GAD) and mood disorders. Thus, individuals that consider emotions as aversive or unpleasant (negative beliefs) tend to avoid them, and in order to manage emotion-related experiences they use ER strategies such as rumination, an ongoing cognitive activity contributing to long-term distress or even psychopathology.

Generally, the current study represents a wider framework toward understanding the important role beliefs about emotions play in the understanding of emotion dysregulation, as delineated by several theories, researches and clinical observations (Gross \& Thompson, 2007; Werner \& Gross, 2010). In line with our results, we assume that beliefs about specific emotions may affect the choice and the maintenance of different ER strategies. Individuals' behaviour regulation has been demonstrated to be affected by personal goals/values (Carver \& Sheier, 1998), thus a similar influence might be hypothesized for emotion regulation too. We sustain that also ER is motivated by personal goals connected with specific beliefs. For example, a person might want to control anxiety in order to demonstrate he/she is strong, or rational, or able to manage his/her own reactions. Different people might have different goals, thus the same ER strategy may be adaptive in some cases but maladaptive in others. Given the correlational nature of our data, it is impossible to establish cause-effect implications; therefore we could only discuss associations among our variables. Cause-effect hypotheses might be tested in future studies.

The present data may have important clinical implications for the etiology and the treatment of clinical disorders, specifically for difficulties in coping with emotions. Working with beliefs about emotions is a fundamental part of cognitive and behavioural psychotherapies (Linehan, 1993; Wells, 2008; Clark \& Beck, 2009; Leahy, 2015). Moreover, clarifying the specific beliefs and goals underlying different emotion-regula- 
tion styles could help to understand the specific mechanisms orienting ER. For example, it would be useful to distinguish between adaptive and maladaptive regulation styles, depending on unavailability of goals that individuals want to pursue (Philippot, 2013). Future research could investigate these functional links through experimental manipulations.

Several limitations need to be acknowledged. First, it is important to consider that the cross-sectional nature of the current study makes it impossible to establish causal relationships between variables. Beliefs about emotions may also reflect existing difficulties in ER, and it is probable that they constitute a maintenance factor.

A limitation relates to measurement. The strong correlation between BAEQ and DERS may, in part, be explained by similar content between the items in the respective questionnaires. For example, the DERS item "When I'm upset, I become embarrassed for feeling that way" or "When I'm upset, I have difficulty controlling my behaviours" are similar to the BAEQ item "When I start feeling upset I cannot control it" or "It is embarrassing to feel upset". It is probable that some items of DERS measure beliefs about emotions.

Finally, the data collected in this study came from a non-clinical sample. We investigated a community sample to avoid any confusing correlations that could have emerged in clinical samples from spillover effects or collateral by-products (Kashdan et al., 2006).

\section{Conclusion}

Our study merely provides preliminary data, therefore, calling for further development. Future research might disentangle the interplay among goals-beliefs-ER strategies, as well as the consequences in terms of psychopathology. In effect, experimentally manipulating individuals' goals and beliefs would provide evidence for the role these processes play in orienting the emotion-regulation processes, and also in the field of psychopathology.

\section{References}

Aldao, A., Nolen-Hoeksema, S., \& Schweizer, S. (2010). Emotion-Regulation Strategies across Psychopathology: A Meta-Analytic Review. Clinical Psychology Review, 30, 217-237. http://dx.doi.org/10.1016/j.cpr.2009.11.004

Alloy, L. B., Abramson, L. Y., Hogan, M. E., Whitehouse, W. G., Rose, D. T., Robinson, M. S., Kim, R. S., \& Lapkin, J. B. (2000). The Temple-Wisconsin Cognitive Vulnerability to Depression Project: Lifetime History of Axis I Psychopathology in Individuals at High and Low Cognitive Risk for Depression. Journal of Abnormal Psychology, 109, 403-418. http://dx.doi.org/10.1037/0021-843X.109.3.403

Bargh, J. A., \& Williams, L. E. (2007). On the Nonconscious of Emotion Regulation. In J. J. Gross (Ed.), Handbook of Emotion Regulation (pp. 429-445). New York: Guilford Press.

Bateman, A. W., \& Fonagy, P. (2004). Mentalization-Based Treatment of BPD. Journal of Personality Disorders, 18, 36-51. http://dx.doi.org/10.1521/pedi.18.1.36.32772

Bond, F. W., Hayes, S. C., Baer, R. A., Carpenter, K. M., Guenole, N., Orcutt, H. K., Waltz, T., \& Zettle, R. D. (2011). Preliminary Psychometric Properties of the Acceptance and Action Ques- 
tionniare-II: A Revised Measure of Psychological Flexibility and Experiential Avoidance. Behavior Therapy, 42, 676-688. http://dx.doi.org/10.1016/j.beth.2011.03.007

Borkovec, T. D., Alcaine, O., \& Behar, E. (2004). Avoidance Theory of Worry and Generalized Anxiety Disorder. In R. G. Heimberg, C. L. Turk, \& D. S. Mennin (Eds.), Generalized Anxiety Disorder: Advances in Research and Practice (pp. 77-108). New York: Guilford Press.

Boulanger, J., Hayes, S. C., \& Pistorello, J. (2010). Experiential Avoidance as a Functional Contextual Concept. In A. Kring, \& D. Sloan (Eds.), Emotion Regulation and Psychopathology (pp. 107-136). New York: Guilford Press.

Campbell-Sills, L., \& Barlow, D. H. (2007). Incorporating Emotion Regulation into Conceptualizations and Treatments of Anxiety and Mood Disorders. In J. J. Gross (Ed.), Handbook of Emotion Regulation (pp. 542-559). New York: Guilford Press.

Carver, C. S., \& Scheier, M. F. (1998). On the Self-Regulation of Behavior. Cambridge: Cambridge University Press. http://dx.doi.org/10.1017/cbo9781139174794

Carver, C. S., Scheier, M. F., \& Weintraub, J. K. (1989). Assessing Coping Strategies: A Theoretically Based Approach. Journal of Personality and Social Psychology, 56, 267-283. http://dx.doi.org/10.1037/0022-3514.56.2.267

Chambless, D. L., \& Goldstein, A. J. (1981). Clinical Treatment of Agoraphobia. In M. Mavissakalian, \& D. H. Barlow (Eds.), Phobia: Psychological and Pharmacological Treatment (pp. 103-144). New York: Guilford.

Clark, D. A., \& Beck, A. T. (2009). Cognitive Therapy of Anxiety Disorders. New York: Guilford Press.

Clark, D. A., \& Beck, A. T. (2010). Cognitive Theory and Therapy of Anxiety and Depression: Convergence with Neurobiological Findings. Trends in Cognitive Science, 14, 418-424.

Cooper, S. E., Miranda, R., \& Mennin, D. S. (2013). Behavioral Indicators of Emotional Avoidance and Subsequent Worry in Generalized Anxiety Disorder and Depression. Journal of EXperimental Psychopathology, 4, 556-583.

Dan-Glauser, E. S., \& Gross, J. J. (2013). Emotion Regulation and Emotion Coherence: Evidence for Strategy-Specific Effects. Emotion, 13, 832-842. http://dx.doi.org/10.1037/a0032672

De Castella, C., Golding, P., Jazaieri, H., Ziv, M., Dweck, C. S., \& Gross, J. J. (2013). Beliefs about Emotion: Links to Emotion Regulation, Well-Being, and Psychological Distress. Basic and Applied Social Psychology, 35, 497-505. http://dx.doi.org/10.1080/01973533.2013.840632

Diamond, L. M., \& Aspinwall, L. G. (2003). Emotion Regulation across the Life Span: An Integrative Perspective Emphasizing Self-Regulation, Positive Affect, and Dyadic Processes. Motivation and Emotion, 27, 125-156. http://dx.doi.org/10.1023/A:1024521920068

Ellis, A. (2003). Early Theories and Practices of Rational Emotive Behavior Therapy and How They Have Been Augmented and Revised during the Last Three Decades. Journal of Rational Emotive and Cognitive Behavior Therapy, 21, 219-243. http://dx.doi.org/10.1023/A:1025890112319

Fonagy, P., \& Target, M. (2003). Psychoanalytic Theories: Perspectives from Developmental Psychopathology. London: Whurr Publishers Limited.

Gratz, K. L., \& Roemer, L. (2004). Multidimensional Assessment of Emotion Regulation and Dysregulation: Development, Factor Structure, and Initial Validation of the Difficulties in Emotion Regulation Scale. Journal of Psychopathology \& Behavioral Assessment, 26, 41-54. http://dx.doi.org/10.1023/B:JOBA.0000007455.08539.94

Greenberg, L. S. (2002). Emotion-Focused Therapy: Coaching Clients to Work through Their Feelings. Washington DC: American Psychological Association. http://dx.doi.org/10.1037/10447-000 
Greenberg, L. S., \& Safran, J. D. (1990). Emotion in Psychotherapy. New York: Guilford Press.

Gross, J. J. (1998). The Emerging Field of Emotion Regulation: An Integrative Review. Review of General Psychology, 2, 271-299. http://dx.doi.org/10.1037/1089-2680.2.3.271

Gross, J. J. (2013). Emotion Regulation: Taking Stock and Moving Forward. Emotion, 13, 359365. http://dx.doi.org/10.1037/a0032135

Gross, J. J., \& John, O. P. (2003). Individual Differences in Two Emotion Regulation Processes: Implications for Affect, Relationships, and Well-Being. Journal of Personality and Social Psychology, 85, 348-362. http://dx.doi.org/10.1037/0022-3514.85.2.348

Gross, J. J., \& Levenson, R. W (1997). Hiding Feelings: The Acute Effects of Inhibiting Negative and Positive Emotion. Journal of Abnormal Psychology, 106, 95-103. http://dx.doi.org/10.1037/0021-843X.106.1.95

Gross, J. J., \& Thompson, R. A. (2007). Emotion Regulation: Conceptual Foundations. In J. J. Gross (Ed.), Handbook of Emotion Regulation (pp. 3-24). New York: Guilford Press.

Hayes, A. F. (2013). Introduction to Mediation, Moderation and Conditional Process Analysis. Guilford Press.

Hayes, S. C., Luoma, J. B., Bond, F. W, Masuda, A., \& Lillis, J. (2006). Acceptance and Commitment Therapy: Model, Processes and Outcomes. Behaviour Research and Therapy, 44, 1-25. http://dx.doi.org/10.1016/j.brat.2005.06.006

Hayes, S. C., Strosahl, K., \& Wilson, K. G. (1999). Acceptance and Commitment Therapy: An Experiential Approach to Behavior Change. New York: Guilford Press.

Hayes, S. C., Wilson, K. G., Strosahl, K., Gifford, E. V., Follette, V. M., \& Stosahl, K. (1996). Experiential Avoidance and Behavioral Disorders: A Functional Dimensional Approach to Diagnosis and Treatment. Journal of Consulting and Clinical Psychology, 64, 1152-1168. http://dx.doi.org/10.1037/0022-006X.64.6.1152

Heide, F. J., \& Borkovec, T. D. (1984). Relaxation-Induced Anxiety: Mechanisms and Theoretical Implications. Behaviour Research and Therapy, 22, 1-12.

http://dx.doi.org/10.1016/0005-7967(84)90027-5

Iverson, K. M., Follette, V. M., Pistorello, J., \& Fruzzetti A. E. (2012). An Investigation of Experiential Avoidance, Emotion Dysregulation, and Distress Tolerance in Young Adult Outpatients with Borderline Personality Disorder Symptoms. Personality Disorders, 3, 415-422. http://dx.doi.org/10.1037/a0023703

Kashdan, T. B., Barrios, V., Forsyth, J. P., \& Steger, M. F. (2006). Experiential Avoidance as a Generalized Psychological Vulnerability: Comparisons with Coping and Emotion Regulation Strategies. Behaviour Research and Therapy, 44, 1301-1320. http://dx.doi.org/10.1016/j.brat.2005.10.003

Lazarus, R., \& Folkman, S. (1984). Stress, Appraisal and Coping. New York: Springer.

Leahy, R. L. (2015). Emotional Schema Therapy. New York: The Guilford Press.

Linehan, M. M. (1993). Cognitive-Behavioral Treatment for Borderline Personality Disorder. New York: Guilford Press.

Maio, G. R., \& Esses, V. M. (2001). The Need for Affect: Individual Differences in the Motivation to Approach or Avoid Emotions. Journal of Personality, 69, 583-614. http://dx.doi.org/10.1111/1467-6494.694156

Manser, R., Cooper, M., \& Trefusis, J. (2012). Beliefs about Emotions as a Metacognitive Construct: Initial Development of a Self-Report Questionnaire Measure and Preliminary Investigation in Relation to Emotion Regulation. Clinical Psychology and Psychotherapy, 19, 235-246. http://dx.doi.org/10.1002/cpp.745 
Mennin, D., \& Farach, F. (2007). Emotion and Evolving Treatments for Adult Psychopathology. Clinical Psychology: Science and Practice, 14, 329-352. http://dx.doi.org/10.1111/j.1468-2850.2007.00094.x

Northoff, G., Heinzel, A., de Greek, M., Bermpohl, F., Dobrowolny, H., \& Panksepp, J. (2006). Self-Referential Processing in Our Brain-A Meta-Analysis of Imaging Studies on the Self. NeuroImage, 31, 440-457. http://dx.doi.org/10.1016/j.neuroimage.2005.12.002

Papageorgiou, C., \& Wells, A. (2001). Metacognitive Beliefs about Rumination in Recurrent Major Depression. Cognitive and Behavioral Practice, 8, 160-164. http://dx.doi.org/10.1016/S1077-7229(01)80021-3

Philippot, P. (2013). Emotion Regulation: A Heuristic Paradigm for Psychopathology. Journal of Experimental Psychopathology, 4, 600-607.

Robinson, M. S., \& Alloy, L. B. (2003). Negative Cognitive Styles and Stress-Reactive Rumination Interact to Predict Depression: A Prospective Study. Cognitive Therapy and Research, 27, 275-291. http://dx.doi.org/10.1023/A:1023914416469

Rottenberg, J., \& Gross, J. (2003). When Emotion Goes Wrong: Realizing the Promise of Affective Science. Clinical Psychology: Science and Practice, 10, 227-232. http://dx.doi.org/10.1093/clipsy.bpg012

Selby, E. A., Anestis, M. D., \& Joiner, T. E. (2008). Understanding the Relationship between Emotional and Behavioral Dysregulation: Emotional Cascades. Behaviour Research and Therapy, 46, 593-611. http://dx.doi.org/10.1016/j.brat.2008.02.002

Shapiro, N. (1995). An Analogue of Agoraphobic Avoidance as Attachment-Related Symptomatology. Unpublished Master's Thesis, Washington DC: Department of Psychology, The American University.

Swenson, C. R., Sanderson, C., Dulit, R. A., \& Linehan, M. M. (2001). The Application of Dialectical Behavior Therapy for Patients with Borderline Personality Disorder on Inpatient Units. The Psychiatric Quarterly, 72, 307-324. http://dx.doi.org/10.1023/A:1010337231127

Tamir, M., John, O. P., Scrivastava S., \& Gross, J. J. (2007). Implicit Theories of Emotion: Affective and Social Outcomes across a Major Life Transition. Journal of Personality and Social Psychology, 92, 731-744. http://dx.doi.org/10.1037/0022-3514.92.4.731

Taylor, S. (1995). Anxiety Sensitivity: Theoretical Perspectives and Recent Findings. Behaviour Research and Therapy, 33, 243-258. http://dx.doi.org/10.1016/0005-7967(94)00063-P

Taylor, S., Koch, W. J., \& Crockett, D. J. (1991). Anxiety Sensitivity, Trait Anxiety, and the Anxiety Disorders. Journal of Anxiety Disorders, 5, 293-311. http://dx.doi.org/10.1016/0887-6185(91)90030-W

Watkins, E. R., \& Baracaia, S. (2001). Why Do People Ruminate in Dysphoric Moods? Personality and Individual Differences, 30, 723-734.

Wells, A. (2008). Metacognitive Therapy for Anxiety and Depression. New York: Guilford Press.

Werner, K., \& Gross, J. J. (2010). Emotion Regulation and Psychopathology. A Conceptual Framework. In A. M. Kring, \& D. M. Sloan (Eds.), Emotion Regulation and Psychopathology. A Transdiagnostic Approach to Etiology and Treatment (pp. 13-37). New York: Guilford Press.

Williams, K. E., Chambless, D. L., \& Ahrens, A. (1997). Are Emotions Frightening? An Extension of the Fear of Fear Construct. Behaviour Research and Therapy, 35, 239-248. http://dx.doi.org/10.1016/S0005-7967(96)00098-8

Zeman, J., Shipman, K., \& Suveg, C. (2001). Anger and Sadness Regulation: Predictions to Internalizing and Externalizing Symptoms in Children. Journal of Clinical Child and Adolescent Psychology, 31, 393-398. http://dx.doi.org/10.1207/S15374424JCCP3103_11 
Submit or recommend next manuscript to SCIRP and we will provide best service for you:

Accepting pre-submission inquiries through Email, Facebook, LinkedIn, Twitter, etc. A wide selection of journals (inclusive of 9 subjects, more than 200 journals)

Providing 24-hour high-quality service

User-friendly online submission system

Fair and swift peer-review system

Efficient typesetting and proofreading procedure

Display of the result of downloads and visits, as well as the number of cited articles

Maximum dissemination of your research work

Submit your manuscript at: http://papersubmission.scirp.org/

Or contact psych@scirp.org 